\title{
Fortuitous Discovery of a Bochdalek Hernia in an Adult
}

Khadija L*, Hajar A, J amal EF and Issam E-N

Department of Radiology, Mohammed V Military

Teaching Hospital, Faculty of Medicine and Pharmacy,

Mohammed V University, Rabat, Morocco

*Corresponding author: Laasri Khadija, Department of Radiology, Mohammed V Military Teaching Hospital, Faculty of Medicine and Pharmacy, Mohammed V

University, Rabat, Morocco

Received: May 14, 2021; Accepted: J une 08, 2021;

Published: June 15, 2021

\section{Keywords}

Diaphragmatic hernia; Bochdalek hernie; Adult

\section{Clinical Image}

Bochdalek hernia is the most common type of congenital diaphragmatic hernia. It is due to a defect in the posterior attachment of the diaphragm muscle, subsequent to a failure of pleuroperitoneal membrane closure in utero.

Bochdalek hernia is often asymptomatic in adults, hence, it is fortuitously discovered as an incidental finding on CT scan. Alternatively, it may be diagnosed only after complications occur, such as empyema, cardiac tamponade and gastrointestinal strangulation.

CT usually demonstrates a fatty mass above the diaphragm (Figure 1: arrow), which may be associated with other organs entrapment. Coronal and sagittal reformatted images show the diaphragmatic defect (Figure 2: arrows).

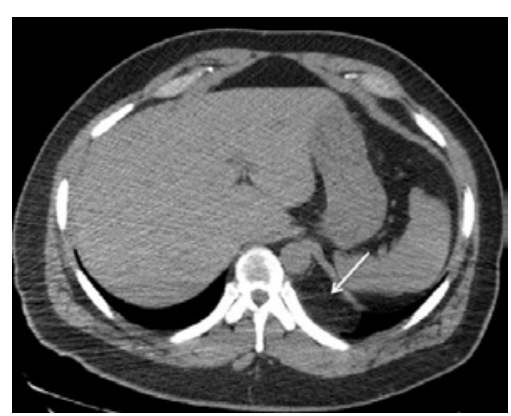

Figure 1: Axial abdominal CT scan image showing a left sided fat containing Bochdalek hernia (arrow).

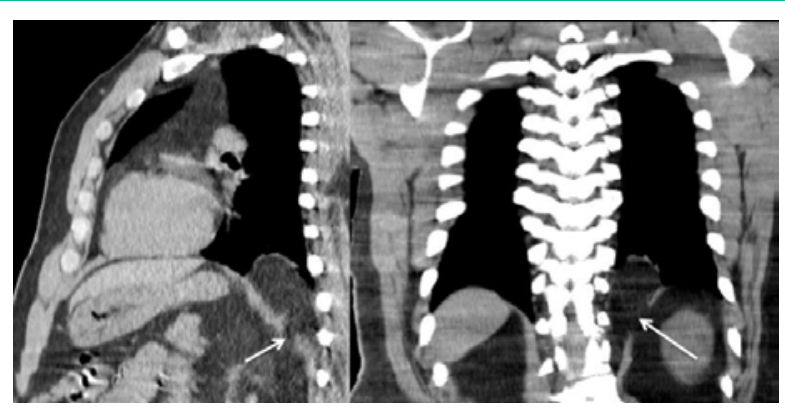

Figure 2: Coronal and sagittal CT scan images demonstrating fat herniation throughout a posterior diaphragmatic defect (arrow). 